\title{
Historiografia e a escravidão africana no paraná: alguns apontamentos
}

\author{
Airton de Moraes $^{I}$ \\ Rita de Cássia Galdin Rocha
}

\section{RESUMO}

Este artigo, analisa quatro visões historiográficas produzidas ao longo do século $X X$, referente ao escravo africano presente na província paranaense. Cada qual dentro do seu contexto, elaborou um discurso priorizando elementos que vinham ao encontro da sua problemática. Sendo assim, as "verdades" expostas pelos diferentes historiadores mostraram ser verdades provisórias, já que cada presente seleciona o passado que deseja e o vê com as lentes do seu tempo.

Palavras-chave: visões historiográficas, escravidão africana, província paranaense.

Neste texto pretendemos analisar como alguns autores examinaram a questão da escravidão negra na Província do Paraná. ${ }^{3}$ Escolhemos autores de distintas correntes e temporalidades: Romário Martins, Cecília Westphalen, Eneliza de Lima e Eduardo Spiller Pena.

A obra História do Paroná de Romário Martins, chegou a ser adotada em diversos locais e momentos pelas escolas da rede pública como manual didático, sendo que seu principal tema, é gênese do povo paranaense. Considerado grande historiador e pensador paranaense, era jornalista por

1 Graduado em História e mestrando em Educação na Universidade Estadual de Londrina.

2 Graduada em História e especialista em História Social e Ensino de História na Universidade Estadual de Londrina.

3 Nesse período a Cápitania de São Paulo englobava a região conhecida como Paraná. Neste texto usaremos o termo Paraná para designar genericamente a 5 Comarca Paulista, que após 19/12/1853, tornou-se Província do Paraná.

4 Com exceção do Romário Martins, os referidos autores são docentes ligados à academia paranaense. A saber: Cecília Westiphalen (falecida), foi docente da Universidade Federal do Paraná; Enezila de Lima, docente do Departamento de História da Universidade Estadual de Londrina e Eduardo Spiller Pena ligado ao Departamento de História da Universidade Tuiuti do Paraná. 
profissão e socialista combativo a exemplo de vários companheiros de geração como Júlio Perneta e Dario Vellozo. Sentiu a influência dos intelectuais estudiosos das raças no Brasil, entre eles - Roquete Pinto, Nina Rodrigues e Sílvio Romero, autores defendiam o "branqueamento" da população brasileira. Martins foi um bom pesquisador, sendo que os documentos que consultou no Museu Paranaense, no Instituto Histórico e Geográfico Paranaense, no Arquuivo Nacional e Arqquivo do Estado de São Paulo, foram as bases que alicerçaram suas inúmeras obras.

O seu trabalho sobre a história do Paraná é o resultado de um processo iniciado por intelectuais paranaenses que buscavam a consolidação da incipiente província. Para tal, procuraram criar uma identidade que legitimasse o "ser" paranaense, surgindo assim em Curitiba, o Movimento Paranista. Para Pereira:

Romário Martins, principal figura do Movimento Paranista, elaborará uma série de livros sobre a história do Paraná. Não à toa Romário foi representante paranaense nas discussões sobre as questões de limites com Santa Catarina. Com uma forte influência do positivismo e da demografia, Romário vêo Paraná como um local privilegiado. Partindo de suas riquezas naturais [...] Romário demonstrava o futuro promissor que aguardava o Paraná pois sua localização geográfica the prometia um futuro gigante (PEREIRA, 1996, p.281).

Diante da ênfase dada à questão da natureza prodigiosa, podemos verificar que Martins retrata com riqueza de detalhes a fauna e a flora. $\mathrm{Na}$ primeira parte, analisa o meio físico, especificamente: relevo, rios, clima, bem como as tribos indígenas que habitavam as terras paranaenses. Todas essas "exuberâncias" da natureza narradas pelo autor serviam como legitimação de um Estado promissor, ou seja, estava presente neste discurso " a grandeza da natureza, a primavera eterna, a variedade das flores e a grandeza dos rios e montanbas e não obstante procurando destacar ainda a temáitica do indianismo" (SZEZ, 1996, p. 297).

Outro ponto importante da sua análise, diz respeito à educação cristã que era ministrada na província, isto é, exalta o sistema de catequização dos jesuítas e a conversão dos indígenas pagãos. Fazem parte das preocupações de Romário Martins em sua narrativa, os caminhos históricos utilizados pelas 
expedições que buscavam explorar terras desconhecidas. Essas estradas levavam e traziam rebanho de gado vacum, muar e eqüino do Rio Grande do Sul para São Paulo, parando em pousos e pequenos vilarejos no decorrer do caminho. Segundo Martins "as cidades foram se formando através dos 'pousos' e dos 'currais' na formação das roças. A criação de gado, a lavoura do milho, feijão e trigo e posteriormente comércio da erva-mate obrigaram à vida sedentária os homens de aventuras mineradoras" (MARTINS, 1995, p.274).

Num segundo momento, Martins aborda a economia paranaense do período ressaltando a importância de Paranaguá, onde apareceram notícias das primeiras minas de ouro. Esse fato, conforme relata-nos Martins, contribuiu para a povoação do litoral e, posteriormente, a expansão demográfica atingiria o primeiro planalto paranaense. Nas questões referentes à política, Romário Martins percorre a ação encetada pelos políticos paranaenses para elevação de Comarca para Província, acontecida em 1853, sendo Curitiba escolhida para ser a capital da Província em 1854.

Martins, discute também outros momentos da história paranaense, como por exemplo: a Revolução Farroupilha; o Combate do Cormorant - conhecido episódio da entrada dos escravos africanos ilegais via Porto de Paranaguá; a Revolução Federalista no Paraná e a Campanha do Contestado. No final do seu livro, Martins explora o assunto referente aos administradores públicos, descrevendo os capitães-mores das Capitanias, seus governantes provisórios eleitos e juntas governativas do Paraná.

Para o objeto específico deste artigo, Martins, ao se remeter ao "Africano Escravizado", mostra-nos que esse povo trazido da África influenciou a formação étnica brasileira juntamente com o índio e o colonizador Ibérico, sempre destacando a superioridade européia. Para ele, a inferioridade do negro, começava pela sua religião, uma vez que:

Fetichistas ao extremo, adoravam ídolos de grosseira confecção e até mesmo simples pedaços de osso, penas, etc. Alguns autores, porém, atribuem-lhes noção de uma divindade superior, o Zaambi ou Zumbi, servida por sacerdotes de grande influência (MARTINS, 1995, p. 153).

5 Este é o título de um sub capítulo que está presente no VI capítulo intitulado: FATORES ÉTNICOS FUNDAMENTAIS do livro de Romário Martins. 
Esta citação, bem como a sequiência do seu texto, no qual ele descreve as práticas de "bruxarias" e o uso de fórmulas mágicas pelos negros, demonstra a formação positivista de Martins, pois ao considerar uma religião fetichista como inferior, ele se remete a Augusio Comte ${ }^{6}$ que considerava o monoteísmo como uma fase superior ao fetichismo e politeísmo. Neste sentido, Martins considerava que os africanos estariam na parte inicial da evolução, pois para os seguidores de Comte a sociedade passaria por três fases a saber: teológica, metafísica e a positivista.

Romário Martins reforça as suas afirmaçãoes sobre a inferioridade do negro destacando o que seria a sua inabilidade com a arte uma vez que: "Como artistas foram detestáveis. Os seus trabalbos de pintura eram de uma infantilidade sem progresso, e a sua escultura era informe (MARTINS, 1995, p. 153). Também na questão política, Martins argumenta no sentido da inferiordade do negro, salientando que os etíopes eram governados por "déspotas sanguinários", sendo assim, para o autor, ser resgatado e trazido à civilização, era a oportunidade do escravo africano sair das trevas e encontrar a luz, e esta "evolução" fazia com que, na visão de Martins "os sentimentos dos negros escravizados em nosso país [fossem] os melhores possiveis, embora sua pouca capacidade de assimilação da cultura ariana se mosirasse desde logo evidente" (MARTINS, 1995, p. 154).

Quando Martins remete-se à mistura de raça que teria havido no Paraná, é bem enfático em mostrar, que apesar de ter havido uma miscigenação tantos de negros e índios, a raça ariana era mais forte para se impor geneticamente e sendo assim, "se pode prever, ainda para este século, o desaparecimento total dos seus representantes indices etíopes na fisionomia da parte da população acional que the é correspondente" (MARTINS, 1995, p.157). Martins destaca que essa mestiçagem não estava presente na elite governante paranaense, pois a mesma era composta, na sua grande maioria, por representantes oriundos da península Ibérica.

A questão escrava para Romário Martins é periférica, pois segundo o autor, estes "imigrantes" não constituíram grandes plantéis no Paraná devido

\footnotetext{
6 Augusto Comte (1798 - 1857) nasceu na França e desenvolveu um método que ficou conhecido como positivista, na qual a sociedade estava sempre em evolução sendo que o ápice seria o estágio positivista ou científico. In: BLACKBURN, Simon. Dicionário Oxford de filosofia. Consultoria da edição brasileira, Danilo Marcondes. Rio de Janeiro: Jorge Zahar Editnr, 1997, pp. 65-66.
} 
ao tipo de atividade econômica da região, ou seja, a criação de gado. Mas o principal aspecto é a visão do autor como sendo cultural, religiosa, politicamente inferior, tendo portanto, pouco contribuido para a formação do Estado, visto que a raça superior ariana predominaria sobre as demais.

Passaremos agora a obra de Cecília Westphalen, autora que pertencia ao grupo de historiadores pertencentes à Universidade Federal do Paraná. 0 trabalho de Westphalen se destaca pela maneira minuciosa utilizada para reconstruir a história paranaense. Especificamente na obra organizada por Faissal El-Khatib e escrita em conjunto com Pillatti Balhana e Pinheiro Machado, Westphalen analisou no primeiro volume da obra, História do Paraná, toda a questão da economia e sociabilidade que resultou na formação da população paranaense. Utilizando fontes como os Relatórios de Província, Boletins do Arquivo Municipal, Matrículas de entradas de escravos, relatos de viajantes como o de Roberto Avé-Lallemant e autores como Octávio Ianni e Rui Wachowicz, Westphalen busca recriar a formação do Paraná tradicional.

Trabalhando com censos populacionais, a autora destaca a importância do indígena, do negro e do branco na formação paranaense. Westphalen salienta, porém, que no século XVII havia dificuldades em precisar o número de habitantes presentes no território, haja vista a falta de dados para as comprovações. Entretanto, segundo a autora, no século XVIII teve início o processo de sistematização dos dados, ou seja, as informações passaram a ser coletada através do censo populacional, proporcionando assim, condições para a análise demográfica do período. 0 censo populacional realizado no século XVIII proporcionou uma visão dimensionada da questão da mão-de-obra empregada no trabalho da agricultura, pecuária, mineração e atividades extrativas.

Entre os apontamentos realizados pela autora, a questão do trabalho indígena merece destaque, uma vez que havia dificuldade na imposição do trabalho forçado ao índio, pois o mesmo tinha amparo legal não podendo, portanto, ser escravizado. Westphalen destaca que embora houvesse a lei, também coexistia a não observância da regulamentação, fazendo com que a própria legislação acabasse por indicar situações em que a mesma pudesse ser violada. A Carta Régia de 5 de novembro de 1808 observa que os índios apreados poderiam ser utilizados no serviço que fossem designados. Com a Lei de 27 de outubro de 1831 tal ato foi revogado, pois a lei conferia ao indígena a liberdade total sem imposição de condições. 
Outro elemento formativo na construção do panorama populacional, segundo Westphalen, foi a presença do escravo negro vindo da África e também de seus descendentes, nascidos no Brasil - conhecidos como crioulos. No censo registrado em 1772, relativo a Capitania de São Paulo, foi verificável a presença marcante de escravos nas vilas e freguesias, sendo relevante o número de cativos na Vila de Paranaguá, ou seja, do total de 3193 habitantes 1414 eram listados como escravos. Para a autora

[...] o censo de 1772 caracteriza a população quanto à sua condição jurídica, ou seja, população livre e escrava, está última registrada de maneira global, sem especificar o sexo ou a idade dos escravos. A população escrava representava 28,8\% do total dos habitantes atingidos pelo censo, porém, observa-se que, na população de Paranaguá, os escravos alcançaram proporções mais elevadas, ou seja, de 44,2\% dos seus habitantes (WESTPHALEN, 1969, p. 118).

A autora afirma que o número de cativo era muito relevante para 0 período - século XVIII -, mas diferentemente de outras regiões do Brasil, no Paraná havia uma pequena quantidade de cativos por plantéis. Das 309 propriedades analisadas em 1844, o número médio de escravos não ultrapassava cinco cativos por senhor, estabelecendo assim, 226 proprietários com esse tipo de plantel, ou seja, "0 número médio de escravos em Paranaguá era pequeno, pois, 73\% dos proprietários possuíam entre 1 a 5 escravos somente, e menos de dez proprietários, isto é, 3\% dos mesmos, possuíam 30 ou mais escravos" (WESTPHALEN, 1969, p. 124). Além disso, embora os cativos fossem preparados para diversas atividades como o serviço de pedreiro e carpinteiro, a grande maioria estava ocupada com a agricultura de subsistência, isto é, envolvidos no setor primário, trabalhando com a lavoura.

Quanto ao quesito cor, Westphalen ressalta que o censo realizado anteriormente ao século XIX não forneceu dados precisos nem em relação à populaçã̃o livre ou a escrava. Mas, a partir do século XIX e com bastante ênfase no século XX, a questão referente à cor foi incluída no recenseamento aparecendo, assim, com maior frequência nos levantamentos a diferenciação da população entre brancos, negros, mulatos e pardos. 
Evidentemente, foi sempre muito difícil uma delimitação precisa dos grupos de cor, tanto pela sua multiplicidade devida à imensa variedade de cruzamentos, como pelo processo de 'branqueamento social', característicos das estruturas demográficas latino-americanas, onde, de um modo geral, muito habitante de ascendência mestiça são considerados brancos (WESTPHALEN, 1969, p. 128).

Para Westphalen, semelhantemente com o plano nacional, aqui no Paraná a composição dos grupos étnicos diferenciados foi de suma importância na constituição social e econômica do Estado. Todas as nacionalidades estavam inseridas no processo de formação do Paraná tradicional, havia negros cativos e livres e também população de origem européia. Mas é importante lembrar que, segundo a autora, a partir de meados do século XIX, especificamente com o fechamento do tráfico, faltou mão-de-obra escrava no Estado, principalmente por ocasião do deslocamento dos cativos da Província do Paraná para as grandes fazendas de café na Província de São Paulo ocasionando, assim, a desagregação da sociedade campeira, modificando e diminuindo a quantidade de escravos e propiciando "a entrada de novos contingentes populacionais trazidos pelo fluxo migratório que se intensifica no Brasil motivado, principalmente, pela escassez de mäo-de-obra na agricultura, tanto de exportação, como na de subsistência" (WESTPHALEN, 1969, p. 126).

Dentro desse contexto, Westphalen salienta a importância da abertura da imigração para suprimento de mão-de-obra trabalhadora proporcionando, assim, a movimentação do país. Para tal, a nação necessitava principalmente de colonos que fossem disponíveis para o manuseio com a terra. Segundo a autora, a fundamentação étnica paranaense que havia legitimado presenças como a do índio, do português e do negro soma-se a partir de então, aos elementos europeus na composição do quadro demográfico do Paraná. A grande variedade étnica foi impressa à população paranaense através dessas imigrações, construindo o quadro populacional como um "verdadeiro mosaico étnico-cultural, no qual estão representados povos e culturas os mais diversos" (WESTPHALEN, 1969, p.128), fazendo com que, o crescimento demográfico paranaense fosse acelerado a partir do século XX.

A terceira obra a ser analisada é "A vila de Curitiba: 1765-1820 estudo da Dinâmica Econômico-social de uma comunidade", de Enezila de Lima, texto esse que foi sua Tese de Doutoramento em História Social defendida na. 
Faculdade de Filosofia, Letras e Ciências Humanas da Universidade de São Paulo (USP), defendida em 1982. No seu trabalho, Lima faz uma análise dos primórdios da "colonização" curitibana, mostrando dos primeiros mineradores até o ciclo da erva-mate. 0 ano de 1765, escolhido como ponto de partida, tem uma particularidade histórica para a capitania de São Paulo ao qual o Paraná pertencia, ou seja, nesse ano São Paulo recuperou a autonomia administrativa perdida para a capitania do Rio de Janeiro. Esse fato, segundo a autora, poderia ser visto por dois aspectos, uma vez que a população dessa parte meridional da colonia portuguesa perderia a "liberdade administrativa", mas em compensação atrairia a atenção da metrópole para uma região que não fazia parte do eixo exportador. A tese tem seu limite temporal datado em 1820, momento que 0 ciclo da erva-mate jáse estabilizara sendo o principal produto da quinta comarca paulista. 0 seu trabalho está dividido em três capítulos, a šaber: o quadro físico e a humanização da paisagem; o planalto curitibano e a economia colonial; a estrutura social.

No primeiro capítulo, Lima relata a condição geográfica paranaense, mostrando as dificuldades enfrentadas pelos "pioneiros" para transposição das barreiras naturais, bem como as particularidades do clima temperado presente no primeiro planalto paranaense - Curitiba -, grosso modo, similar ao clima do velho continente. A exploração dessa localidade deu-se no século XVII, com o advento da mineração, sendo que "os primeiros povoadores efetivos dos campos de Curitiba foram esses paulistas, direia ou indiretamente ligados ao bandeirismo" (LIMA, 1982, p.22). Um fato destacado no texto é a pouca presença de "escravos etíopes" no início do povoamento do planalto de Curitiba, uma vez comparado com a população de "negros da terra" ., que segundo Lima motivado pela baixa rentabilidade da região.

A questão econômica foi à base da discussão do segundo capítulo. Logo de início Lima apresenta-nos um fato que modificou a região econômica e demograficamente, ou seja, a descoberta de ouro na região das Minas Gerais, uma vez que a produção aurífera "paranaense" era de difícil extração e a rentabilidade não seria mais atraente quando comparada às novas minas da região ao norte da província paulista. Nesse contexto, Lima destaca que a

\footnotetext{
${ }^{7}$ Negros da terra é a denominação que se usava para denominar o índio.
} 
economia paranaense se restringiu à cultura de subsistência e a criação de gado vacum, atividades essas, que segundo a autora, utilizavam parca mãode-obra escrava. A produção aurífera da região das Minas Gerais, que impôs uma drástica redução econômica e demográfica da região, desencadeou, num momento ulterior, uma grande procura por animais seja para a carga, ou consumo. Conforme salienta a autora, esse ciclo econômico contribuiu para a ampliação do número de plantéis de escravo, pois segundo o censo analisado por Lima "o aumento de escravos corresponde exatamente às regióes onde a criação de gado era aividade que possibilitava lucro certo e também possibilitava o comércio de excedentes das roças de mantimentos" (LIMA, $1982, \mathrm{p} .125)$.

Para Lima, a presença do negro na atividade agrícola no Paraná tem. que ser analisada de forma diferenciada do contexto colonial brasileiro, pois a base da agricultura paranaense não estava atrelada à exportação. Segundo a. autora, a agricultura no Paraná era basicamente de subsistência o que dispensava a mão-de-obra escrava, mas existiram fazendas que além de criarem gados, plantavam gêneros alimentícios que servia para abastecer as tropas e nessas, os negros cativos eram usados como "agricultores". A questão do agregado é outro ponto explorado pela autora, que afirma a enormidade de escravos alforriados que continuavam nas fazendas prestando serviço ao antigo senhor, pois suas condições de ex-escravo geralmente impediam o liberio de conseguir trabalho longe da antiga senzala.

0 ciclo da erva-mate foi outra atividade na qual o negro esteve presente, seja na produção ou transporte da erva até o porto de Paranaguá. Segundo Lima "Verifica-se que em 1798 apenas 0,43\% dos escravos estavam empregados nas atividades ligadas à manufatura da erva-mate [...] no censo de 1820 estes ocupavam 19,76\% na escala de ocupaçoes" (LIMA, 1982, p.166), o que mostra uma acentuada mudança no contexto, já que a produção da erva-mate no século XVII estava atrelada a pessoas pobres livres.

Lima relata-nos a presença de escravos especializados como: carpinteiro; pedreiro; padeiro; sendo assim era "reduzido o número de oficiais do termo de Curitiba. É possivel que a existência de uma reduzida atividade artesanal esteja vinculada à presença do escravo nessas aividades" (LIMA, 
1982, p.178). Nota-se também, segundo Lima, a presença de escravo de ganho", apesar de "näo se saber em que atividades eram empregadas, mas sua existência é comprovada pelo censo de 1820, quando cinco famílias declaravam "viver do jomal de seus escravos" (LIMA, 1982, p.181).

No último capítulo de sua tese, Lima mostra que desde a origem da cidade de Curitíba há convivência de homens livres e escravos. Nos censo, os escravos são descritos juntamente com as posses do senhor o que the reduz " $\vec{a}$ condição de coisa e sua equiparação aos irracionais [ao] vir especificado ao lado das posses de outro bomem esclarece também sua condição de propriedade, de domínio, de sujeição, de mercadoria" (LIMA, 1982, p.186). Segundo a autora, a estrutura social era fortemente marcada pela cor da pele, uma vez que o homem branco tinha relações sexuais com negras e índias, mas no que tange ao casamento ele era endogâmico, sendo assim:

a endogamia presente na organização da família patriarcal constituía-se en um poderoso sistema de dominação econômica e política, com vistas a assegurar e adquirir prestígio e 'status', como também para preservar a integridade social do grupo racial dominante, na periferia do núcleo central a mulher escrava desempenhava a função de satisfazer as necessidades sexuais e emocionais de sues senhores familia (LIMA, 1982, p.193).

Passaremos agora a análise do livro O jogo da Face, Eduardo Spillen Pena, publicado em 1999. Através de peças literárias e dramatúrgicas, jomais daépoca, relatos de viajantes, listas nominativas e inventários post-mortem, o autor realizou um levantamento da questão escrava no Paraná. Através do debate com Fernando Henrique Cardoso e Octávio Ianni, o autor buscou desconstruir a visão "coisificada" do cativo, mostrando-o como agente latente do sistema. Através de referenciais teóricos como Edward Thompson e Genovese, Pena verificou os embates e os conflitos inerentes aos diferentes interesses de ambas as classes, tanto a dos senhores como dos cativos.

No primeiro capítulo "Os números da posse" o autor discute os padrões

8 Escravo de ganho era considerado o cativo que recebia do seu trabalho diário uma parcela do seu recurso, ficando o restante com o seu senhor. Conferir em MOURA, C. As injustiças do clio. O negro na bistoriografia brasileira. Belo Horizonte: Editora Nossa Terra, 1990. pp.163-164 
de sociabilidade dos cativos na Província do Paraná, através da documentação a respeito dos padrões de posse, das indicações e comparações de idade, das condições dos plantéis paranaenses e do perfil da população escrava buscando, assim, conhecer como se configurava o cotidiano do cativo dentro do seu espaço geográrico. De maneira particular trata da questão do trálico interprovincial, destacando os principais motivos da desagregação do escravismo paranaense e a falta de mão-de-obra escrava a partir de 1850.

Na segunda parte do livro, no capítulo "Do estigma à Experiência", Pena utiliza a literatura e a dramaurgia da época para investigar o cotidiano escravo além das leituras "coisificantes" procurando desvendar a sua própria leitura e interpretação sobre os acontecimentos que cercavam a vida domésica na província. Através de jornais do período infere sobre assuntos de ordem moral, tais como: ajuntamentos em festas; ações da polícia; laços familiares; promiscuidade; casamentos entre os cativos. Destaca também as aç̃es da elite paranaense em relação ao medo constante que vivia frente a uma populaçäo negra e cativa e os dispositivos legais utilizados por essa elite para manter os cativos "nos seus devidos lugares".

Pena mostra-nos, no subcapítulo intitulado "Do castigo e do poder público: os paradoxos da lei", que o Estado começa a "invadir" o espaço privado, seja para prender um cativo que excedeu no álcool, impetrar valores de alforrias, ou ainda, determinar a quantidade de açoites que o cativo "merecia". Essa prática perdurou até 1886 quando foi promulgada uma Lei proibindo o uso do espaço público como lugar de correção. Outra forma de usar o poder público na atividade escravista, era na questão da captura dos esciavos fujões, prática essa perfeitamente justificada pelas autoridades da época como forma de manter a ordem pública. No que tange às sevícias impostas pelos feitores ao escravo, a partir de 1871, o Estado passou a questionar os "exageros". Segundo Pena, não se cogitava a eliminação dos castigos físicos e sim a moderação, pois as correções eram necessárias para manter a ordem.

Outro ponto aventado pelo autor diz respeito a possibilidade da morte do senhor por dois motivos distintos, ou seja, diante da possibilidade de transferência o pavor tomava conta do plantel de escravos, pois a era sempre temida; e em outros casos, era a tão sonhada liberdade que poderia chegar com a morte do senhor, pois muitas vezes, as alforrias estavam condicionadas a morte do senhor. 
Pena explica-nos que alguns herdeiros tentaram vários subterfúgios para impedir o acesso do escravo à manumissão, sendo assim, o autor é enfático em mostrar que o escravo "brigou" na justiça pelos seus direitose, independente do resultado da querela, o que importa para o autor é que os escravos não aceitaram passivamente a condição a eles imposta.

Ao comentar sobre a lei de 26 setembro de $1871^{9}$, Pena salienta que esta tinha como objetivo central formar trabalhadores, mas na prática teve outro efeito, pois a partir de então os escravos conseguiram "impor", através da justiça, o direito a compra de sua liberdade e se auto-avaliar, isto é, independente da vontade do seu senhor de vendê-lo ou não, o escravo poderia requisitar sua "alforria" desde que tivesse condições para pagá-la. Em Curitiba, o autor relata-nos casos que os "etíopes", através de decisão judicial, "compraram" sua liberdade por um preço diferente do que foi pedido pelo seu "dono". A Lei Saraiva-Cotegipe editada 15 anos após a Lei Rio Branco, tenta atenuar esta situação estabelecendo uma tabela com valores fixos por faixa etária.

E bastante latente no trabalho do autor a questão da validação do cativo como sujeito do processo histórico, pois abandonando completamente as visões "coisificadas" do escravo, Pena recupera o cativo como um ser atuante na vida cotidiana de Curitiba no século XIX, revelando as astúcias dos escravos frente ao sistema escravista.

\section{Considrações Finais}

Em síntese, ao fazermos as análises dos autores mencionados, constatamos que apesar do objeto de estudo - escravo - estar inserido no mesmo espaço geográfico e temporal, existem diferentes abordagens historiográficas. Sendo assim, cada qual "enxergou" o escravo na Província do Paraná de forma sui generis, ou seja, "cada presente seleciona um passado que deseja e lhe interessa conbecer. A bistória é necessariamente escrita e reescrita a partir das posições do presente, lugar da problemática da pesquisa e do sujeito que a realiza"(REIS, 2002, p.9).

\footnotetext{
${ }^{9}$ A Lei de 28 de setembro de 1871 - Lei Rio Branco, mais conhecida por Lei do Ventre Livre
} 
Exemplo disso, são os estudos de Romário Martins, escrito no final do século XIX e início do século XX. Martins está preocupado em suas análises com uma história total, fazendo com que sua obra, seja uma "enciclopédia" de conhecimento do Paraná, compreendendo os assuntos relacionados à política, natureza e énias. Especificamente no assunto relacionado à escravidão, o autor menciona sucintamente o escravo como parte integrante do sistema, não apresentando em seu livio nenhuma problemática em relação à escravidão, ou seja, ela está simplesmente inserida no contexto social abarcado pelo autor, servindo como pano de fundo para um enredo no qual, o ator principal, tem pele mais alva que o descendente etiope. Martins é enfático em sua assertiva no que tange à contribuição negra, pois pertencendo a uma "raça inferior", só trariam bárbaros costumes a família paranaense. Este mal, segundo Martins, foi afastado devido à miscigenação com os europeus, uma vez que esta raça por ser superior, paulatinamente contriburia para o desaparecimento total dos representantes e das características fisionômicas etiopes em parte da populacão nacional. O que podemos perceber na leimura de Romário Martins é que o colonizador poruguês teria feito um bem ao resgatar o etíope e introduzi-lo em sua colônia no Atântico Sul. No caso paranaense, segundo Martins, os filhos de Cam"10 tiveram mais sorte ainda, pois a produção agrícola não estava voltada para exportação, o que tomou sua "estadia" mais "amena", en síntese, para Martins, esses "migrantes" muito pouco ofereceram para provincia paranaense.

Em uma análise posterior, com abordagem diferente de Romário Martins, Cecilia Westphalen, concebe o escravo africano como parte integrante do sistema. E. verificável em seus estudos, uma mudança de perspectiva historiográfica em relação à obra de Romário Martins, isto é, trabalhando com uma ampla ela lança sobre o cativo um novo olhar Para tanto, novas questões são colocadas como: quantidade de cativos no plantel paranaense; ocupação desses escravos no cotidiano das regiõos urbanas e rurais. Tematizando a formação dos grupos étnicos são trazidas à tona outras perspectivas, na quais as três etnias - índios, negros e brancos - atuariam concomitantemente na formação da população, sendo que, a predominância dos brancos se dá por uma questão numérica e não por ser uma "raça" superior como

\footnotetext{
${ }^{10}$ Segundo a explicação religiosa, usada pelos europeus no sentido de justificar o tráfico de escravos africanos, "os negros são descendentes de Cam, ílho de Noé, Amaldiçoado pelo pai por ter desrespeitado quando o encontrou [Noé] embriagado, numa postura indecente" Verificar: MUNANGA, Kabengele. Negritude: usos e sentidos. São Paulo: Ática, 1986, p. 15; BORTOLINI, José (coordenação editorial) Bíblia de Jerusalém: nova edição, revista e ampliada. São Paulo: Paulus, 2002, p. 46.
} 
destacara Romário Martins. A autora também demonstra uma preocupação em relação à movimentação dos cativos dentro do Paraná e a modificaçãa do panorama populacional do Estado.

Enezila de Lima, demonstra em seu trabalho a inserção do cativo nesta estrutura social da Província. Lima também relata a presença de escravos especializados na província paranaense mostrando as nuances que permeavam a difícil relação social entre libertos e cativos desde a origem da cidade de Curitiba. Ao analisar a estrutura social paranaense, mostra-nos uma nítida diferença entre senhores e escravos, isto é, o escravo como propriedade é "coisificado" e, portanto, em nenhuma parte do trabalho o negro cativo aparece questionando sua condição e, mesmo, quando alforriado permaneceria ao lado do antigo senhor como agregado, mostrando sua total dependência. Um fato destacável em sua análise é a presença do escravo de ganho no período em questão. Para alguns autores que escreveram a partir de 1980, no quais está incluido Pena, estes escravos tinham uma certa mobilidade e independência em relação ào senhor, o que contraria a visão de total submissão no qual "o escravo apenas registrava e espelhava, passivamente, os significados sociais que the eram impostos" (CARDOSO, 1977, p.125).

Diferentemente dos outros autores analisados, Pena mostra um cativo extremamente atuante, certamente ligado ao seu senhor, mas também capaz de arquitetar planos de fugas, de roubos e maneiras de driblar a polícia local. Através de leituras sui generis de novas e velhas fontes, foi capaz de recriar a presença do cativo dentro do sistema escravista, de enxergá-lo diante das redes de solidariedades, dos laços familiares e das negociações frente à liberdade. Rompendo completamente com a historiografia da escravidão até então desenvolvida sobre o Paraná, que entendia o cativo como parte inerte do sistema, o autor demonstra os espaços de negociação com o senhor. Pena consegue fazer com que o leitor perceba o "jogo da face" na qual o escravo não esperava passivamente o momento tão sonhado da liberdade, mas sabia "usar e manipular" em seu favor as leis e recursos disponíveis para sua manumissão. Um exemplo desta influência estaria presente na Lei do Ventre Livre, ou seja, "O texto final da lei [...] foi o reconbecimento legal de uma série de direitos que os escravos haviam adquirido pelo costume e a aceitação de alguns objelivos das luitas dos negros" (CHALHOUB, apud PENA, 2001, p.285).

o que constatamos ao analisar estes quatros autores e suas respectivas obras, é que cada presente analisa um fato por um determinado ponto, uma 
vez que cada tempo histórico enxerga o objeto com as suas "lentes", proporcionando uma "visão parcial do passado" e, portanto, não podemos pensar em "verdades histórias" e sim em "verdades históricas parciais", pois:

Em cada presente, o que se tem é uma visão parcial, uma articulação original do passado e do futuro. A história é visada segundo perspectivas diversas, e, com 0 avanço do tempo, as proposições históricas mudam. Todo o historiador é marcado por seu lugar social, por sua 'data'e por sua pessoa. Vêem-se sempre aparecer obras novas sobre o mesmo assunto. À medida que o tempo passa, novas experiências são acrescentadas às precedentes, e novas esperas são desenhadas. 0 passado é assaltado por interrogações novas, que oferecem respostas diferentes das anteriores. Em cada presente há um esforço de compreensão: de autolocalização pela rearticulação de passado e futuro (REIS, 2002, p.11)

Corroborando com José Carlos Reis, Adam Schaff mostra-nos outro ponto relevante. Para ele, o contexto histórico e o mundo ao qual o pesquisador está incluído, influenciam o seu conhecimento, portanto, ele não consegue ser imparcial em suas análises pois, "O sujeito desempenha um papel ativo no conbecimento bistórico, e a objetividade desse conbecimento contém sempre uma dose de subjetividade. Senão, esse conbecimento seria a-bumano ou sobre-bumano" (SCHAFF, 1995, p.280).

Em síntese, todas as leituras e abordagens realizadas são necessárias para a construção do processo histórico, sendo assim, o entendimento das relações estabelecidas pelos autores com suas fontes são importantes para a compreensão desse processo. Porém, devemos salientar a importância da leitura crítica das obras tomando o cuidado de não incorporar velhos discursos transvestidos de novos paradigmas. Portanto, temos que entender o contexto no qual foi escrita a obra, analisando a data e o local da publicação, o público alvo e a formação do autor, pois ao contrário, podemos realizar uma leitura enviesada e o seu corolário poderá levar a incorporações de conceitos anacrônicos ou a uma crítica injusta, uma vez que "a expressão individual ocorre dentro de um idioma geral, de que aprendemos a classificar as sensações e a entender as coisas pensando dentro de uma estrutura fornecida por nossa cultura" (CHALHOUB, 2001, p.16). 
Bibliografia

BLACKBURN, Simon. Dicionário Oxford de filosofia. Consultoria da edição brasileira, Danilo Marcondes. Rio de Janeiro: Jorge Zahar Editor, 1997

BORTOLINI, José (coordenação editorial) Bíblia de Jerusalém: nova edição, revista e ampliada. São Paulo: Paulus, 2002.

BURKE, Peter. A Escola dos Annales: A revolução francesa da historiografia. Trad. Nilo Odalia. São Paulo: Ed. UNESP, 1997.

CARDOSO, Fernando Henrique. Capitalismo e Escravidão no Brasil Meridional. Paz e Terra, 1977.

CHALHOUB, Sidney. Visões de Liberdade. Uma História das últimas décadas da escravidão na corte. Rio de Janeiro. Cia das Letras, 2001.

CORREA, Sílvio M. de Souza. O negro e a historiografia brasileira. Revisía Àgora. v. 6, n.1, jan./jun.2000.

COSTA, Emília.Viotti da. Da senzala a colônia. Momentos decisivos. $3^{\text {a }}$.ed. São Paulo; Brasiliense, 1985 .

FALCON, Francisco J. C. A identidade do historiador. Revista Estudos Históricos. Rio de Janeiro: FGV, v. 9, 1996.

FICO, Carlos \& POLITO, Ronald. A historiografia brasileira nos últimos 20 anos tentativa de avaliação crítica. In: MALERBA, Jurandir (org). A velha bistória: teoria, método e historiografia. Campinas-SP: Papirus, 1996.

FREYRE, Gilberto. Casa Grande e Senzala. 25. ed. Rio de Janeiro: José Olympio, 1987. IÁNNI, Octávio. As metamorfoses do escravo. São Paulo. Difel, 1962.

LIMA, Enezila de. A vila de Curitiba: 1765-1820 estudo da Dinâmica Econômico-social de uma comunidade. São Paulo: USP, 1982, (Tese de doutoramento).

MARTINS, Romário. História do Paraná. Curitiba: Travessa dos Editores, 1995.

MATTOSO, Kátia M. de Queiroz. Ser escravo no Brasil. São Paulo: Brasiliense, 1982.

MOURA, Clovis. As injustiças do clio. O negro na bistoriografia brasileira. Belo Horizonte: Editora Nossa Terra, 1990. 
MUNANGA, Kabengele. Negritude: usos e sentidos. São Paulo: Ática, 1986.

PENA, Eduardo Spiller. O jogo da face. A astúcia escrava frente aos senhores e à lei na Curitiba Provincial. Curitiba: Aos quatro ventos, 1999.

PEREIRA, Luis Fernando Lopes. "Paranismo: cultura e imaginário no Paraná dos anos 20". ARRUDA, Gilmar \& DENIPOTI, Cláudio. (org). Cultura e Cidadania. v.1. Londrina: ANPUH/PR, 1996.

REIS, José Carlos. As identidades do Brasil. De Varnhangem a FHC. $5^{\circ}$ ed. Rio de Janeiro: Editora da FVG, 2002. . A bistória entre a filosofia e a ciência. São Paulo: Ática, 1996.

RODRIGuES, Raimundo Nina. Africanos nos Brasil. São Paulo: Cia Editora Nacional, 1945

SCHAFF, Adam. História e Verdade. Trad. Maria Paula Duarte. São Paulo: Martins Fontes, 1995.

SZEZ, Cristiane Marques. "O conceito de região: discurso e representação do Paraná". ARRUDA, Gilmar \& DENIPOTI, Cláudio. (org). Cultura e Cidadania. v.1. Londrina: ANPUH/PR, 1996.

WESTPHALEN, Cecilia População do Paraná tradicional. In: EL-KHATIB, Faissal História to Paraná. Curitiba: Grafipar, 1969. 


\section{Historiography and African slavery in Parana: some questions}

\section{ABSTRACT}

This article, analyzes four visions historiography produced along the century XX, regarding the slave present African in the province paranaense. Each one inside of his context, it elaborated a speech prioritizing elements that came to the encounter of his problem. Being like this, the exposed "truths" for the different historians showed to be true temporary, since each present selects the past that he wants and he sees him with the lenses of his time.

Key words: historiography, African slavery, province paranaense. 